\title{
The Development Model for School Administrators the office of the Basic Education Commission in Thailand 4.0
}

\author{
Asst.Prof.Dr.Phumphakhawat Phumphongkhochasorn \\ Director Institute Innovation Technology Educational and Research, Eastern Institute of Technology Suvarnabhumi (EITS), \\ Thailand \\ phumphakhawat.ps@gmail.com
}

\begin{abstract}
This research aimed to 1) to study the elements of the development model for school administrators of the Office of the Basic Education Commission in Thailand 4.02 2) to develop the model of the school administrators of the Office of the Basic Education Commission in Thailand. Land 4.0 and 3) assess the appropriateness of the development of the model for the administrators of the Office of the Basic Education Commission in Thailand 4.0 using a combined approach. There are 4 steps of research: 1) study documents and related research. With the administration of educational institutions of the Office of the Basic Education Commission in Thailand 4.02) Develop a model for administrators of school administrators of the Office of the Basic Education Commission in Thailand 4.0 with Delphi techniques from management experts to excellence 19 persons 3) analyzed the elements of the development pattern of the administrators of the Office of the Basic Education Commission in Thailand 4.0 by analyzing the elements; The statistics used for data analysis were percentage, range, quartile, mean, standard deviation and elemental analysis.

Research findings

1.The study of the administrators of the Office of the Basic Education Commission in Thailand 4.0 found that it consisted of 5 important components: Characteristics of self-development of modern leadership, modern management development skills, roles, duties, morality, ethics and competencies of school administrators of the Office of the Basic Education Commission in Thailand 4.0 2.Development of the model for school administrators of the Office of the Basic Education Commission in Thailand 4.0 found that there are 5 main components: leadership, vision, morality, ethics, knowledge, competence and information and technology. 3. The level of suitability of the development of the model for the school administrators of the Office of the Basic Education Commission in Thailand 4.0 overall and the aspects are very good.
\end{abstract}

Keywords

School Administrators, Office of the Basic Education Commission, Model Development, Thailand 4.0

Article Received: 10 August 2020, Revised: 25 October 2020, Accepted: 18 November 2020

\section{Introduction}

. Nowadays, Thai society has fully entered the digital world, making socio-economic activities run rapidly, with high competition, increasing access to massive amounts of information online through the online world, resulting in a change in child characteristics, and the government announced Thai policies. Land 4.0 aims for Thailand to step out of the middle-income trap and move towards a highincome country by employing economic, social innovation and high-quality human resource development to drive the country. Upgrading the quality of human resources in the country to prepare manpower to be a key mechanism for the development of Thai economy and society to the regional and international economic stage. 4.0 "by the National Institute for Child and Family Development, Mahidol University in collaboration with the Office of Health Promotion Foundation (Thai Health Promotion Foundation) in exchange for education management with creative integration to meet the needs of the developing society. Will step into the digital age for strategic target areas that the Thai education system must develop to support the Thailand policy 4.0 of the government from a joint research study between August and the World Bank, based on the experience of international education reform, is the development of quality midsize schools located in all subdistricts of Thailand. The center has good quality and is the center of the area and works in connection with the mechanism of the Provincial Education Office already in operation of the Ministry of Education. Those schools will also be able to develop the workforce in that district and then expand the development to smaller neighboring schools and will be able to cover the quality development of more than $50 \%$ of the nation's children and youth entering the labor market in the future. It is a pleasure that this idea has been implemented in the Ministry of Education, namely the magnetic school that OBEC has begun to operate.

The 20-Year National Strategy (2017-2036), which is due to the link between the National Strategy and the 12th National Development Plan, in the state of the problem that is the source of the concept of the National Strategy, namely, the development of the country is not continually There are various development plans and strategic plans, allocation and use of modular budgets, the determination of the future of nations is largely done by the government sector and developed countries will have a national strategy through the 20-year National Strategy Framework. (2017-2036): "The country is still prosperous, still standing as a developed country. With the development according to the philosophy of sufficiency economy "leads to the development of happiness for Thai people and responds to the achievement of national interests in improving the quality of life Create high income and create happiness for Thai people. Society is stable, equitable and fair, the country can compete in the economy. Thailand 4.0 is committed to transform the economy into a "Value - Based Economy" or "Innovation-driven" economy, which is still stuck in a "do more and less" economic model. Are "Doing very little" 
The most important drive for change in at least three dimensions is the shift from commodity production to commercial commodity. Innovation changes from driving the country with the industrial sector towards technologydriven creativity and innovation and shifted from an emphasis on manufacturing to more services.

Education 4.0 (Education 4.0) is teaching that teaches students the ability to creatively integrate their knowledge everywhere in the world to develop innovations to meet the needs of society. Far away in many dimensions, for example, never taught students to think by themselves Most of them still teach to do the same problem. Another story is that learners are not familiar with society, most of them spend their time in the online world with games, shopping, chatting, Facebook Line, and Instagram are mostly illusory societies where technology is not wrong, but there are two areas of coin, so is technology used in what ways are it useful? It is difficult and challenging for those who must teach in this era because the teaching and learning in the age 4.0 had to let the students use technology in their own learning. Let them dare to think and dare to be wrong, but they all still must be within the framework that society wants or can accept, not always being smart, always able to think new and be creative, but not acceptable to society. Using technology that is cost-effective.

Learning in Thailand 4.0 era, teachers cannot be teachers alone. But students must be self-taught by teachers to design learning, train themselves to be a coach, and facilitate (Facilitator) in learning, and must design the learning process that will enable students to develop skills. In the pursuit of self-knowledge, the key skills that children and youth in Thailand 4.0 should have are learning and innovation skills or $3 \mathrm{R}$ and $4 \mathrm{C}$ with $3 \mathrm{R}$ components: reading, writing and mathematics. (Arithmetic) and $4 \mathrm{C}$ is analytical thinking (Critical Thinking, Communication, Collaboration and Creativity, including life and professional skills and information, media, and technology skills. And new educational management, etc.

School administrators must be developed to have quality and standards suitable for high professionalism, have a professional license as required by law, as well as have a professional organization, educational institution administrators and educational administrators as well. Today's executives will need to develop conceptual skills to be able to determine the direction of development of their own departments or educational institutions more accurately and in a direction (do the right things). As a result of those executives being more decentralized, more important decisions will have to play a role as a policy developer rather than a policy leader. And with the trend of rapid social change, the need for managers with these skills higher than ever before. Human skills skills) are also important and necessary because in the era of decentralized management, people in the organization will have higher quality and standards this requires management to play a role in negotiating with an educational interest group (interest group). Groups) in various schools in society and communities Therefore, the need for leadership (leadership) is higher than in command or control, as in the past. About principles, concepts and theories based on scientific approaches to gain technical skills skills) are still essential as well, because they reflect a certain degree of managerial professionalism and are the ones that will enable new ideas. That can be appropriately applied to the realities of the agency or local area (Wirot, 2013)

The role of school administrators without borders, despite the national movement in education administration of Thailand 4.0 era since December 2010, with a meeting of high school administrators by the Office of the Commission. Basic education includes academic conferences, written articles on the skills of the Thailand 4.0 Era, due to the lack of advanced skilled workforce, which is a global trend, but the movement in such matters is uninterrupted by everyone. The lack of host organization, which is the key to coordinating and taking this matter seriously, poses a great challenge for school administrators in the era of no boundaries, being inactive, doing the same things as they used to wait for the policy. From above but unilaterally while the political and government instability All damage to the country's human capital development results in the nation's lack of competitiveness and interests. When the border was officially opened in 2015, today's start might be a little slow. But it is not too late to act, and school administrators at all levels, as the organization's authority, must decide on the implementation of the strategic plans and missions of the schools for which they are responsible, establishing quality for the future based on: Skills of Thailand Era 4.0 and monitor and monitor the implementation of serious actions (Rossukhon, 2012)

In conclusion, the changes in various fields the world in the era of Thailand 4.0 has inevitably stepped into the school fence, the role of the school administrator as the leader of the organization, which is the most important and influential engine on the quality of education. Therefore, it is very important to develop the development model for school administrators of the Office of the Basic Education Commission in Thailand 4.0 if the school administrators do not develop themselves to keep up with the global changes in the era of Thailand 4.0. Or unable to adapt to the era of rapid change, may cause problems in organizational management and affect the quality of education. Foundation in Thailand 4.0 to be used as a guideline for the development of schools to be more efficient and effective.

\section{Research Objectives}

Research on the development of educational quality and standards of secondary schools under Bangkok under the framework of the new educational quality assurance has the following research objectives.

1) To study the quality development characteristics and educational standards of secondary schools under Bangkok under the new educational quality assurance framework.

2) Establish a model for developing the educational quality and standards of secondary schools. Under the new education quality assurance framework.

3) Assess the development of educational quality and standards of secondary schools under Bangkok under the new educational quality assurance framework. 


\section{Research Method}

Step 1: Study the concept, document and research work related to the development model for school administrators of the Office of the Basic Education Commission in Thailand 4.0.

Step 2: Create a model for the development of school administrators of the Office of the Basic Education Commission in Thailand 4.0 using the Delphi Technique process to find consistency from expert opinions. The number of experts is 30 people who have knowledge and ability in basic education management in Thailand 4.0 era.

Step 3: Analyze the key components of the development model for the school administrators of the Office of the Basic Education Commission in Thailand 4.0 with Factor Analysis.

Step 4 Evaluation (Evaluation) when the 3 processes are completed. In the process, the researcher used the results as a rating questionnaire (Rating scale questionnaire) for 101. administrators under the Primary Educational Service Area Office in Chonburi Province to vote for another opinion. With more complete

\section{Sample Selection}

\section{For the Delphi technique.}

The research population was school administrators under the Office of the Basic Education Commission, experts in educational administration, education administrators, and educational administration scholars with achievements in school administration in the Thai era. Land 4.0 experts in school administration, education administrators, academics in education administration and basic school administrators use a specific selection method of 30 people. Based on qualifications Experience in school administration and has a strong reputation in education.

2. For inquiries using population questionnaires for inquiry using questionnaires for basic education institution administrators under the Primary Education Service Area Office in Chonburi Province, total 220 schools.

The sample group for the questionnaire was school administrators under the Primary Education Service Area Office in Chonburi Province by using Crazy and Morgan's open grid method (Krejcie \& Morgan, 1970). 101 schools 1 student per school by sampling.

\section{Construction and development of research tools}

\section{Research instruments}

1.The interview form is an open-ended, unstructured question about basic education institution administrators in Thailand 4.0 era, divided into 3 parts:

Part 1 General information of the interviewee

Part 2 Composition of basic education institution

administrators in the era of Thailand 4.0

Part 3 Other Suggestions

2. Opinion questionnaire, evaluation forms 5 levels (Rating Scale) on the format of basic school administrators in the era of Thailand 4.0 divided into 2 parts:

Part 1 General information of respondents
Part 2 Format for basic education institution administrators in Thailand 4.0 era obtained from interviews with 150 experts.

Part 3 Other Suggestions

\section{Tool construction process}

Part 1 is an open-ended, unstructured question. On the format of basic school administrators in the era of Thailand 4.0

1. Study concepts and theories about basic educational institution administration. Concepts and theories of educational institution administrators in the era of Thailand 4.0; concepts and theories of educational management in the century 21 and related research to be used as information in determining the scope and content of the interview.

2. Analyze the variables and points to be studied to formulate questions in the interview.

3. Create an unstructured interview form from the conclusions obtained from the analysis of concepts, theories, and related research for interviewing administrators of educational institutions under the Primary Education Service Area Office in Chonburi Province. Academic Qualifications in Educational Administration

4. Bring the completed interview form to the advisor for examination.

5. Revise the interview form according to the advice of the advisor.

6. Use the revised interview form to interview 30 experts for Round 1.

7. Bring the interview form for each expert to confirm the accuracy from the second interview.

8. Using data from interviews of 30 experts in the second round to use content analysis (Content Analysis) and asked experts to answer the 3rd round of questions by doing a questionnaire to estimate 5 levels (Rating Scale) using the Liket estimation scale according to the following criteria:

A score of 5 means that opinion is at the highest level.

Weight score of 4 means there is a high level of opinion.

Weight score of 3 means there was a moderate level of opinion.

Weight score of 2 means there is little opinion.

A score of 1 means that opinion is the least level.

To analyze the median (Medien), the mode and to find the range between quartiles (Interquatile Range) to create a new Questionnaire to inquire about 101 school administrators under the Primary Education Service Area Office in Chonburi Province.

Part 2 Comment Questionnaire 5-level evaluation form (Rating Scale)

1. Bring the completed questionnaire in item 8 for the advisor to check for accuracy and initial suitability.

2. Revise the questionnaire according to the advice of the advisor and bring it to 5 experts to check for the content validity test and find the conformity index by item or IOC (Index of Item Objective). Congruence) and consider selecting questions with an IOC value More than 0.50 to be a questionnaire for income of 100 items. 
3. Revise the questionnaire according to the recommendation of the expert and the recommendation of the advisor.

4. Bring the revised questionnaire to tryout with the school administrators. Under the primary education area office in Rayong, Chanthaburi and Tart provinces, which were similar and not a sample group used in this research, 30 people to analyze the reliability (Reliability) using the Alpha-Coefficient.) By specifying the confidence criteria for the whole questionnaire must be at a value of 0.60 or more (Boonchom, 2002)

5. Tryout questionnaires were used to collect data from schools under the Primary Educational Service Area Office in Chonburi Province by sampling of 101 schools, 1 student per school, and analyzed data using a package program.

\section{Data Collection}

\section{Procedures for collecting information from the interview.}

1.1 Submit a letter requesting a courtesy to collect information before proceeding to the interview.

1.2 The researcher used the interview method by traveling to interview by himself.

1.3 Send a thank you letter Interview specialists who provide information on educational institution management.

\section{Procedures for collecting data from questionnaires.}

2.1 Investigators follow up and collect data for each school setting.

2.2 Introduce self-introduction books with questionnaires asking for help in answering the survey of 101 schools administrators. One school student, each school researcher collects questionnaires by themselves, some mailed and in addition, some online storage. The researcher took the completed questionnaire to create a form on Google. drive, and then send a link to request cooperation from the sample group to fill in the information online for Ready to request a convenient date to receive the questionnaire.

2.3 The researcher collected questionnaires at the appointed time, checked the completeness of the questionnaires and sent a thank you note, which the researcher received the questionnaire back from the sample $100 \%$

\section{Data analysis}

\section{Analysis of information from the interview.}

1.1 Information obtained from the interview Use content analysis

\section{Analysis of data from questionnaires}

2.1 General data of the respondents were analyzed by using quantitative statistics as follows: Frequency and Percentage 2.2 Data on the model of basic education institution administrators in the era of Thailand 4.0 The researcher analyzed the data by using a package program by distributing the frequency and finding the percentages in the optional part, using the mean and standard deviation in the scaled segment estimates the assignment of an answer or option at each level using the following criteria (Boonchom, 2002).

The average score of $4.50-5.00$, meaning that is most suitable.

The average score of $3.50-4.49$ means that the suitability is at a high level.

The mean score of $2.50-3.49$ means that the suitability is in the medium level.

The average score of 1.50-2.49 means suitability is at a low level.

The average score of $1.00-1.49$ means that the suitability is the least.

2.3 Analysis of data obtained from expert interviews is a questionnaire in round 2 and 3 to calculate median, mode, and interquartile range. Range) using a program.

\section{Research Findings}

Objective 1. The results of the research revealed that development model for school administrators of the Office of the Basic Education Commission in Thailand 4.0 consisted of 5 key components: characteristics of modern management, modern skills. Roles of modern management, morality, and ethics of executives in Thailand 4.0 and the competency of executives in the era of Thailand 4.0 to be used as a guideline and drive the administration

of schools to be efficient and effective1.

Objective 2. The results of the research were to create a model for the development of administrators of the Office of the Basic Education Commission in Thailand 4.0 using the Delphi technique. Technique) from 30 experts from the first round of analysis by Delphi technique and from the Delphi technique Technique) in the 2 nd and 3 rd rounds to verify the accuracy of experts and exploratory factor analysis to examine the weight values of the indicators for each component. The criteria for selection were factor loading of 0.5 or higher. It was found that the development model for school administrators of the Office of the Basic Education Commission in Thailand 4.0 had 5 main components as follows: 1) The leader is composed of eight indicators; the sub-elements have the weight of the indicators in the component (factor loading) was between 0.841-0.651 with a variance of 8.987 and a percentage of variance equal to 7.8472 ). Vision consisted of indicators of 8 subcomponents. loading) was between $0.874-0.654$ with a variance of 7.654 and a percentage of variance of 6.6543 ) Moral and ethical indicators consist of 6 sub-elements. There is a metric weight value in the component (factor loading) was between 0.687-0.698 and had a variance of 5.987 and a percentage of variance of 5.984). Knowledge and competence consisted of 6 indicators of sub-components. between 0.745-0.684 had a variance of 5.45 and a percentage of variance of 4.35 ; and 5) Information, information, and technology It consists of 6 metrics, sub-elements with metric weight values (factor loading) is between 0.698. -0.556 variance was 3.68 and percentage variance was 3.45 , respectively.

Objective 3 . The research results showed that the assessment of the appropriateness of the development model for school administrators of the Office of the Basic Education 
Commission in Thailand 4.0 from the school administrators under the Primary Education Service Area Office in Chonburi Province. 101 people found that the level of suitability of the basic education institution administrators in Thailand 4.0 era, overall and aspects were at a high level, with the mean from descending as follows. Information, information and technology $(=4.21, \mathrm{SD}=0.56)$ including 1) Educational innovations and digital technology And have media knowledge; 2) have communication skills Can communicate in many languages 3) Be knowledgeable and able to use technology professionally 4) creativity can innovate Leadership and 5) Use information (Big Data) for analyzing data and creating a strategic plan $(=4.21, \mathrm{SD}=$ 0.45 ), namely 1) positive attitude. Optimism 2) Lead change in various fields Keep pace with modern events 3) Leadership, empowerment and positive inspiration 4) Good interpersonal relationship 5) Developing Accepting change and new things and 6) always being dependable to others Vision $(=3.98, \mathrm{SD}=0.65)$ ie 1$)$ positive vision Be aware of the past and present situation 2) the future 3) be a forecaster to keep up with the changes of the world 4) be a reformer, developer and visionary 5) being a innovator, always innovating in moral, ethical and 6) Be a human developer towards a stable and sustainable future $(=3.98, \mathrm{SD}=0.60)$, i.e. 1) adhere to the philosophy of sufficiency economy as a management and lifestyle guideline 2) morality, ethics, transparency and accountability 3 ) Be honest, 4) use good governance principles in management and 5) be a role model for teachers. Personnel and students and their knowledge and competence $(=3.98, \mathrm{SD}=0.65)$, namely 1 ) knowledge in science (management principles Regulations and policies) and arts (management techniques, administrative psychology) 2) to learn new science. And continuous self-development 3) a model (model) and new methods of management 4) knowledgeable and skilled in various fields such as English, technology, and 5) able to learn new technology and use it. Correctly in order

\section{Discussion}

The results of the Objective 1 research found that the development model for school administrators of the Office of the Basic Education Commission in Thailand 4.0 consisted of 5 key components: characteristics of modern management, new skills, roles of modern management, morality Ethics of management in Thailand 4.0 and the competency of executives in the era of Thailand 4.0 to be used as a guideline to drive the administration of schools to be more efficient and effective. Consistent with the research Ungkanawin.K (2020), the innovative model of learning that influences the achievement of the School Administration for Learning in the 21 st century, and the concept of executive competency of David McClelland (McClelland). The results of the Objective 2 research were found that the development model for school administrators of the Office of the Basic Education Commission in Thailand 4.0 There is five main components: 1) leadership, 2) vision, 3) morality, ethics, 4) knowledge and ability, and 5) information, information, and technology. Fundamentals in Thailand 4.0 must be knowledgeable, knowledgeable, up to date with technology and information, must develop themselves and pursuit of continuous learning, vision, and academic leadership. Able to supervise and introduce others must have morality, ethics, a good role model and be accepted by teachers, students, educational personnel, and the community in accordance with the research of Rosukon Inchai, Khao Anucha, Kon Puang and Sukanya Chamchoi (2018) studied on the development of self-sufficiency educational institutions. The objective of the research was to 1) study the components of the sufficiency school administration of innovation by interviewing 8 knowledgeable and experienced persons. Only place Innovation through cooperative action research Classified into 2 stages, preparatory and operational, and 3) evaluated the development of innovative sufficiency school management with participatory action research by taking lessons from the cooperation network group. Educational institutions and teachers and student representatives The findings were as follows: 1. The components of the innovation sufficiency school were 2 The levels were: 1) The educational institution level consisted of 6 components: (1) the background of the school (2) the strategy plan of the school (3) the leadership of the school administrators (4) the internal ICT structure of the school ) Government and community support (6) school culture and 2) classroom level The learning management dimension consists of 6 components: (1) learning objectives (2) teacher roles (3) student roles (4) The use of ICT, media and learning resources (5) Networking (6) Multiple outcomes 2. The results of the development of innovative sufficiency school administration through cooperative action research by selecting one target school, which is a learning center based on the philosophy of sufficiency economy in Phitsanulok Province in the preparation stage of the research team establishment Of 21 people and a development team of 15 The people who analyzed the school environment found that most were consistent with the composition of the educational institutions of innovation and brought the weaknesses / obstacles to formulate guidelines and 3 main strategies, namely 1) developing ICT systems to support innovation 2) Promote learning management to be an innovative school. 3) Enhance cooperation with network partners in the development of innovative educational institutes and operational procedures to transform strategies into action plans. Problem solving during operations.

3. Evaluation results for innovation sufficiency school administration development it was found that the results were achieved according to the criteria set, and the success factor was the leadership of the executive. The support of network partners and elements of the administration of the Sufficiency Education Institution, which is a good foundation for the development of the Sufficiency Education Institution. Innovation where every element is related to each other in accordance with empirical data in line with the Lapisun concept. Sinlarat (2009), researching innovation into practice in educational institutions, found that the development of teachers' cooperation and the strength of the management team to drive educational innovation to schools to be successful consists of important factors, namely Collaborate with teachers in the use of innovation and the strength of the management team to use administrative principles and management strategies in educational innovation management so that teachers and teachers cooperate in driving innovation together. The results of the hypothesis testing also found that the ability to manage 
educational innovation in 21 st century had a positive direct influence on promoting the use of learning innovation in educational institutions with a path coefficient of 0.73 effectively. The objective research of item 3 found that the level of suitability of the development model for the education institution administrators of the Office of the Basic Education Commission in Thailand 4.0 overall and individually. Very level this is because the administrators of basic education institutions are now eager to develop themselves to be able to keep up with the rapidly changing world. Therefore, the level of suitability of the basic education institution administrators in Thailand 4.0 era, overall and individually Very level In line with Sornet Aree Sophonphichet (2018) research, we have studied innovation in educational administration towards change "4 Learn" This 21 st century education is a new era of education that focuses on learner development. To have knowledge and skills of the future is education for change (Education for change) focus on learning management aimed at improving the learning quality of the new age learners. Creatively 4 characteristics: (1) learning through creative thinking Provide learners with creative thinking skills as the foundation of the thinking process (2) learn to innovate by themselves, ready for change (3) learn to live together on diversity Focus on providing learners to understand the diversity of people in different societies. Race, society, economy, and culture to learn how to live together happily and (4) learn to share and take responsibility for society, which is a challenge for schools or educational institutions to develop a new paradigm for innovation in educational administration towards the development of transformational education that can connect people development. And community development and building processes develop the learning quality that meets the future world the concept of educational management innovation development that emphasizes the development of a new paradigm of problemdriven education management that can be applied. According to each context of each organization, it is called "Educational Administration Innovation to Change 4 Learn", which is a management innovation for holistic education management with the concept of the development of two dimensions: horizontal dimension. This is a process dimension such as motivation, creating new ideas, applying realism, and defining the process. Vertical dimension, which is the dimension of changer, i.e., internal changer and changer outside the organization. Based on contextualdesigned assumptions they are different for each organization, which must be tried and updated continuously to be successful. In management that leads to constructive change.

\section{Suggestions for the next research}

1. Development model for school administrators of the Office of the Basic Education Commission in Thailand 4.0 should connect various departments, personnel, and activities. To promote and support the operation of the organization to be effective to achieve the desired objectives. And there must be a concept of educational development. The problem should be analyzed. And find solutions to problems that will help in development and facilitate the teaching process and with the development of learning resources, teachers must learn and must adapt with children when technology and innovation change rapidly, teachers cannot become knowledge holders as before because from now on, waiting for textbooks to the teachers are not communicating enough because children now have faster access to information than meeting the teacher.

2. Development model for school administrators of the Office of the Basic Education Commission in Thailand 4.0 must have knowledge Competence, skills, and administrative experience the focus should be on self-study, i.e., lead oneself in learning. Knows what interests you, knows how to find information, how to acquire information, and refine knowledge. Have skills in thinking, planning, and managing your own life.

3. The development model for school administrators of the Office of the Basic Education Commission in Thailand 4.0 must have morality and ethics by choosing to suit the management context and implement the principles until it is a character. Both morality and ethics for oneself, morality for administration and morality and ethics for society

\section{Suggestions for further research}

1. Should continue to research the management problems of the development model for school administrators of the Office of the Basic Education Commission in Thailand 4.0 to be a guideline for solving the administrative problems of basic education administrators.

2. There should be a study of the factors that promote the administrative efficiency of the educational institution administration development model of the Office of the Basic Education Commission in Thailand 4.0 to develop tools that help in the administration for further efficiency.

\section{References}

[1] Areeya S. (2011). Administrative skills of administrators according to the opinions of administrators and teachers under the Office of Chanthaburi Primary Educational Service Area. Thesis M.Ed. Rambhai Barni Rajabhat University.

[2] Boonchom S. (2002). Preliminary research. Bangkok: Suwiriyasat.

[3] Chaiyont P. (2016). School administrators of the new era in the 21 st century. Retrieved December 9, 2016. from: http://conference.edu.ksu.ac.th/file/201608 09_2488101126.pdf

[4] Krejcie, R. \& Morgan, D. (1970). Determining Sample Size for Research Activities. Educational and Psychological Measurement, 30(3), 607-610. 
[5] Kusalin, M. (2011). Science teaching in the 21 st century. Booklet Institute for Innovative Learning. Mahidol University, 22 (6), 6-9.

[6] Nitwadee, J. (2017). The Relationship between Participative Management and Good Governance of Administrators in Schools under the Office of Ratchaburi Primary Education Service Office Area 2. Nakhon Phanom University Journal,7(2), 19-26.

[7] Rossukhon M. (2012). School Administrators's Role in the Age of Globalization. Online Retrieved October 7, 2019.

From http://www.academia.edu/4001681.

[8] Stueber, R. (August 2000). "The Characteristics of an Effective Lutheran High School Administrator", Dissertation Abstracts International. 61(2): 61-05-A.

[9] Thunyanun, K. (2013). The Development for Sustainable Excellent Administration of Labschool Model.PhD. Thesis (Educational Administration). Silpakorn University.

[10] Vicharn P. (2011). The way to create learning for pupils in the $21 \mathrm{st}$ century. Bangkok: Tathata Publication Co., Ltd.

[11] Wirot S. (2013). New educational paradigm, case study of 21 st century education. Bangkok: Thippayawisuth LP.

[12] Charnfan.P. (2013). Teachers' Opinion on Academic Administration of School Network Administrators in Bangkok. Phrom Phiram District 6, Phitsanulok Province Master of Education Thesis Program in Educational Administration Graduate school Thongsuk College. Bangkok.

[13] Phumphongkhochasorn.P.(2020). Factors Affecting Learners' Behavior by Using Innovative Teaching Media Read Learn Run (RLR) as a Base for Teaching and Learning at the Primary Level under the Bangkok Metropolitan Administration For the development of education to Thailand 4.0. Journal of MCU Peace Studies Mahachulalongkornrajavidyalaya
University, Ayutthaya. Vol 8 No 4. JulyAgust 2020.pp.280-294.

[14] Jarumani.N. (2001). Tourism and Tourism Industry Management. Bangkok: Printing HouseOs Printing House.

[15] BenJarongkit.Y. (1999). Analysis of recipients. Bangkok: Faculty of Communication Arts Chulalongkorn University.

[16] Suksawang.S. (2017). Challenges for modern leaders. [Online]. Retrieved 16 December 2017, from https://www.sasimasuk.com/16768188/vuc a-world.

[17] Kongthiang, S. (1999). Educational administration theory. [Online]. Accessed from:

https://thirasakchodcham.wordpress.com/2 015/11/04/. (Date searched: 4 September 2019).

[18] Seels \& Ricchey. (2017). Thai education in the era of Thailand 4.0.[Online]. Accessed from: https://sites.google.com/site/sumet7sbt/thai land-4-0 / karsuksathiyniyukhthailand 40. (Date searched: 7 September 2019).

[19] Sinthaphanon.S. (2010). Innovative teaching and learning to improve the quality of youth. Bangkok: Department of Equity Limited. 9119 Printing Techniques. 